\title{
L'APAD au milieu du gué...
}

Jean-Pierre Chauveau

\section{OpenEdition}

Journals

Édition électronique

URL : http://journals.openedition.org/apad/374

DOI : 10.4000/apad.374

ISSN : 1950-6929

Éditeur

LIT Verlag

Édition imprimée

Date de publication : 15 mars 1992

\section{Référence électronique}

Jean-Pierre Chauveau, «L'APAD au milieu du gué... », Bulletin de l'APAD [En ligne], 3 | 1992, mis en ligne le 05 juillet 2006, consulté le 24 septembre 2020. URL : http://journals.openedition.org/apad/374 DOI : https://doi.org/10.4000/apad.374

Ce document a été généré automatiquement le 24 septembre 2020.

Bulletin de I'APAD 


\title{
L'APAD au milieu du gué...
}

\author{
Jean-Pierre Chauveau
}

1 Avec les deuxièmes "Journées APAD" qui vont se dérouler du 22 au 24 octobre à Montpellier, notre Association va franchir une première étape. En effet, ces journées concrétiseront plusieurs de nos objectifs scientifiques, nous permettront de tirer un premier bilan et seront l'occasion de resserrer nos liens. Le tout, n'en doutons pas, dans la liberté de ton que notre président appelait de ses vœux dans le dernier éditorial...

2 Largement plus d'une centaine de participants sont attendus (sur les quelques 150 membres de l'APAD), ce qui est le signe de la vitalité de notre association. Ce succès de participation ne saura, bien sûr, faire oublier l'absence de ceux qui n'auront pu se déplacer, notamment parmi les adhérents africains. Aussi est-il important que tous ceux-là nous fassent parvenir leurs remarques, critiques, suggestions et toutes offres de participation à la vie de l'association.

3 Ce premier succès - que le déroulement même des Journées devrait confirmer, même si nous avons été un peu pris de court par cette affluence qui dépasse nos prévisions !conforte l'idée que l'APAD répond à un véritable besoin. Pour cela, il nous oblige aussi à nous remettre en question pour mieux répondre aux attentes de tous ceux qui se reconnaissent dans ce projet.

4 Côté positif, on doit enregistrer la croissance des effectifs "apadiens", dont maintenant un bon tiers est constitué de collègues africains. On peut être également satisfait de constater l'organisation de réseaux locaux AP AD dans les pays africains, dont certains sont très actifs (c'est beaucoup moins vrai des réseaux européens !). Satisfaction, enfin, d'avoir pu publier trois bulletins substantiels (celui-ci avec quelque retard!). A propos $\mathrm{du}$ Bulletin : nous introduisons dans la rubrique "Lu et à lire" quelques innovations qui peuvent susciter la contribution de tous : publication de bibliographies thématiques et signalement des travaux publiés par les "apadiens". D'autres améliorations sont certainement possibles, et pour cela, nous avons besoin de tous les avis et de toutes les collaborations...

5 Mais la satisfaction de franchir une étape ne doit pas nous empêcher de préparer la suivante... De ce point de vue des indicateurs "clignotent" et attirent l'attention sur des faiblesses ou des ambiguïtés. On peut en signaler déjà certaines. 
D'abord la prédominance "franco-française" du noyau le plus actif de l'APAD. Certes, cela s'explique par les conditions de lancement du réseau, et, après tout, le problème n'est pas qu'il y a beaucoup de Français mais plutôt qu'il n'y a pas assez de représentants des autres communautés scientifiques ou professionnelles pour initier et soutenir les activités. Mais ce n'est pas une raison pour encourager une dérive facile! Aussi devrions-nous, par exemple, être attentif à l'usage par trop exclusif du français comme langue de travail et faire de plus en plus de place aux autres langues utilisées en commun par les Africains et les Européens. D'autres améliorations, allant dans le même sens, sont aussi envisageables. Ne peut-on pas concevoir que les réseaux nationaux de l'APAD soient, de temps en temps et à tour de rôle, particulièrement chargés de préparer un numéro du Bulletin? Enfin, une rumeur circule selon laquelle les prochaines Journées seraient organisées en Afrique avec la participation d'un réseau national africain...

7 Autres "clignotants", qui concernent cette fois les thèmes et les spécialités représentés à l'APAD. Une écrasante majorité de "ruralistes" d'abord -même si la réflexion, on s'en doute, prend nécessairement en compte les rapports étroits qui unissent le "rural" aux changements sociaux, économiques, politiques et culturels que connaissent les autres composantes des sociétés africaines. Ce biais se manifeste d'ailleurs dans le présent numéro du Bulletin, préparé dans l'esprit des Journées d'octobre. Mais, bien que le thème dominant porte sur "organisations paysannes et associations populaires" (celles-ci n'étant pas nécessairement Rurales), force est de constater que la rubrique "Réflexions et débat" et la plupart des autres rubriques ne brillent pas par la forte participation des spécialistes du milieu urbain, du secteur "informel" ou des problèmes de santé (pour ne prendre que ces exemples)!

On peut aussi noter, au sein des "apadiens", une forte majorité de chercheurs aux dépens de praticiens et de spécialistes du développement - même si ces chercheurs sont souvent fortement impliqués dans l'action et si ces praticiens essayent de trouver à l'APAD le lieu de réflexion qui peut manquer dans leur pratique professionnelle courante...

Enfin, l'incontestable succès de la phase de lancement de l'APAD pose immanquablement de nouveaux problèmes d'organisation et de fonctionnement eu égard aux ressources humaines et matérielles dont nous disposons.

Bien sûr, l'APAD n'est pas partie de rien et ces indicateurs "trahissent" son origine et sa jeunesse. Dans quel sens faut-il gérer son évolution? La discussion, prochainement entamée à Montpellier, méritera d'être débattue dans l'ensemble des réseaux. Pour passer sans encombre le gué... 